\title{
УСЛОВИЯ И ВОЗМОЖНОСТИ ПЕРЕХОДА ЭКОНОМИКИ К ЗЕЛЕНОМУ РОСТУ
}

\section{И.П. Деревяго*}

Рассматривается содержание концепции зеленого роста и основные аспекты, связанные с ее реализацией, включая вопросы оценки природных активов, учета фактора времени, институциональных преобразований. В результате анализа предлагается концептуальная схема, в рамках которой интегрированы и взаимоувязаны основные факторы и элементы, которые играют ключевую роль в процессе перехода к зеленому росту. Разработан подход к оценке соответствия инвестиционной политики требованиям зеленого роста. С учетом результатов оценки сделаны выводы о направлениях ее совершенствования.

Ключевые слова: зеленый рост, инвестиции, природный капитал, экономическая политика, добавленная стоимость.

JEL-классификация: E02, E22, O44, Q56.

DOI: $10.46782 / 1818-4510-2020-4-20-35$

Материал поступил 2.08.2020 2.

Достигнутый масштаб разрушения окружающей среды и усиление дефицита природных ресурсов ставят под сомнение возможность сохранения современного характера и динамики экономического развития. Необходимость повышения его устойчивости подразумевает поиск новой модели роста экономики, которая будет учитывать экологические ограничения. В основу такой модели может быть положена концепция зеленого роста.

Формирование концепции зеленого роста стало закономерным следствием эволюции экономической мысли, развитием ее экологического направления в рамках таких дисциплин, как экономика окружающей среды, экологическая экономика и пр. (Деревяго, 2019а). На сегодняшний день доктрина зеленого роста привлекает все больше внимания экономистов, постепенно выходя на передний план в экономической политике многих государств. Страны ОЭСР официально используют систему показателей зеленого роста для оценки прогресса в экологизации экономического развития. В соответствии с рекомендациями ОЭСР Республика Беларусь с 2017 г. также публикует показатели зеленого рос- та в статистическом сборнике «Охрана окружающей среды в Республике Беларусь». Тем не менее полноценная реализация концепции зеленого роста требует изучения широкого спектра методологических и практических аспектов проблемы. С целью развития исследований в данном направлении в статье рассматриваются вопросы перехода к зеленому росту белорусской экономики.

\section{Общее содержание конщепчии зеленого роста}

В отношении понятия зеленого роста в литературе не существует единой трактовки. Чаще всего зеленый рост рассматривается как средство достижения экологической устойчивости развития. Так, согласно определению ОЭСР, под ним понимается экономический рост при условии сохранения природных активов, которые гарантируют предоставление экологических ресурсов и услуг, необходимых для обеспечения благополучия населения ${ }^{1}$. В данном контексте концепцию зеленого роста можно трактовать как подход к организации эко-

1 URL: https://www.oecd.org/greengrowth/GG_ Brochure_2015.pdf

Деревяго Игорь Петрович (1218pd@gmail.com), кандидат экономических наук, Белорусский государственный университет (г. Минск, Беларусь). 
номики в соответствии с целями и требованиями устойчивого развития.

Увязывая содержание зеленого роста с устойчивым развитием, приходится автоматически признать необходимость пересмотра традиционных критериев экономического прогресса. В первую очередь, это означает переход к более широкому спектру критериев оценки. Если традиционно в качестве основного параметра роста используется ВВП, то, например, повестка устойчивого развития на 2030 г. включает 17 целей, среди которых лишь одна (цель 8) непосредственного касается роста экономики. Такая многокритериальность существенно усложняет проблему формирования целостной и последовательной методологии. Многоцелевой характер стратегии устойчивого развития часто становится источником противоречий, когда реализация одной цели препятствует достижению другой. Концепция зеленого роста в данном случае может выступить в качестве инструмента, направленного на обеспечение внутренней согласованности стратегии. В то же время практическая реализация концепции требует исследования широкого спектра вопросов, связанных с ее адаптацией к условиям конкретной экономической системы и выработкой необходимых мер экономической политики.

Стоит отметить, что при рассмотрении проблемы экономического роста экологический фактор долгое время игнорировался экономистами либо ему отводилась второстепенная роль. Центральное место, как правило, занимали проблемы сбережений, инвестиций, перераспределения доходов, инноваций, внешней торговли (Taylor, 2004). Тем не менее по мере осознания ограниченности возможностей биосферы все большее внимание стала привлекать проблема влияния на развитие экономики природно-ресурсного потенциала. И если изначально приоритет отдавался изучению влияния на экономический рост дефицита сырьевых ресурсов, то со временем на первый план вышли экологические последствия человеческой деятельности. Анализ результатов антропогенного воздействия на биосферу показывает, что мировая производственная система столкнется с необра- тимыми нарушениями в окружающей среде скорее, чем закончатся материальные природные ресурсы. Исходя из этого можно сделать вывод, что возможности перехода экономики к зеленому росту определяются в первую очередь ее способностью соответствовать требованиям экологической устойчивости.

Для успешного применения концепции на практике необходима определенная формализация. В отношении зеленого роста такая формализация требует учета достаточно широкого перечня аспектов, которые прямо или косвенно отражают взаимосвязь различных экологических факторов и экономического развития (Деревяго, 2019a). Рассмотрим основные из них.

1. Природный капитал и его оценка. В некоторых моделях природный капитал наряду с человеческим и физическим выступает в качестве фактора экономического роста. Проведены исследования по стоимостной оценке природных активов в самой различной форме. Демонстрацией подхода по включению природного капитала в совокупное национальное богатство наряду с физическим и человеческим может быть оценка Всемирного банка², которая проводится на регулярной основе.

Особо стоит отметить вклад в изучение влияния природного фактора на развитие экономики интегрированных экономико-климатические моделей. В частности, широкую известность и признание получили исследования У. Нордхауза и Дж. Бойера (Nordhaus, Boyer, 2000) по анализу влияния ущерба от выброса парниковых газов на экономический рост в долгосрочной перспективе. Подобные модели могут использоваться для оценки различных инструментов снижения воздействия на окружающую среду и выработки их оптимальной комбинации.

Тем не менее среди специалистов пока не сложилось единого мнения как в отношении экономического содержания природного капитала, так и методики его оценки. Предметом дискуссии в первую очередь является вопрос о том, насколько различные природные активы соответствуют кри-

${ }^{2}$ URL: https://www.worldbank.org/en/events/2018/ 03/22/the-changing-wealth-of-nations-2018 
териям традиционных рыночных благ. На современном этапе становится все более очевидным, что природный и физический капитал взаимозаменяемы в очень ограниченном диапазоне. Более того, природный капитал сам по себе является достаточно разнородным, а его отдельные элементы могут быть не взаимозаменяемыми. В этой связи все более распространенным становится мнение о необходимости поддержания на приемлемом уровне критически важных для сохранения окружающей среды природных активов, независимо от их цены и степени участия в создании традиционного ВВП (Daly, Farley, 2011).

Критическими элементами природного капитала выступают главным образом экосистемные ресурсы. В отличие от традиционных сырьевых ресурсов, они часто не имеют материальной формы и не обладают свойствами рыночных благ, что ограничивает возможности экономического регулирования в их отношении. В данном контексте важным для формирования концепции зеленого роста аспектом является институциональная среда.

2. Институциональные аспекты зеленого pocma. Роль институтов в экономическом развитии нельзя недооценивать. Институциональное направление занимает важное место в экономической науке, находя дополнительную поддержку со стороны экономистов, когда неоклассическая либо иная господствующая теория не способны убедительно объяснить экономические явления. Теория роста не является исключением. Ряд исследователей в том или ином виде включают в свои модели экономического роста институциональный фактор. Более того, по мнению некоторых экономистов, институты являются главной причиной различий в развитии отдельных государств (Acemoglu, Robinson, 2012).

Не вызывает сомнений, что переход к зеленому росту потребует значительных институциональных преобразований, целью которых должны стать изменения в поведении субъектов экономики. Новая институциональная среда подразумевает переход к экономической модели, ориентированной на сохранение экосистем и их функций. Это, с одной стороны, требует институцио- нального «оформления» природных благ в рамках конкретной системы экономических отношений в качестве экосистемных ресурсов или ином виде, а с другой - формирования соответствующих ценностных приоритетов и инструментов их реализации, которые будут определять характер мотивации экономических субъектов.

Возможность институционализации элементов природной среды, т. е. их интеграции в систему экономических отношений, ограничена так называемым принципом эффективности Р. Коуза, согласно которому транзакционные издержки регулирования не должны превышать выгоды от установления прав собственности на отдельные экосистемные ресурсы или иных способов их институционального «оформления». Учитывая, что ряд природных благ относятся к ресурсам общего доступа, выполнение принципа Коуза на практике часто вызывает затруднения. В данной ситуации основную роль в институциональных преобразованиях играют соответствующие инструменты экономической (и не только) политики, направленные на реализацию ценностных приоритетов зеленого роста, включая налогообложение, бюджетное финансирование и пр. Очевидно, что во втором случае усиливается фактор субъективности, благодаря чему концепция зеленого роста подвергается критике сторонниками традиционного позитивистского подхода к экономике. В то же время в условиях неопределенности сложно сохранять абсолютную объективность. Особенно неопределенность и субъективность увеличиваются, когда речь идет о длительном горизонте планирования.

3. Фактор времени при переходе $\kappa$ зеленому росту. Баланс выгод и издержек при оценке перспектив экономического роста может существенно меняться в зависимости от того, насколько отдаленный период принимается во внимание. На практике существует немало примеров, когда решения, направленные на увеличение текущего ВВП, становились причиной его падения (сдерживания) в будущем.

Поскольку концепция зеленого роста рассматривается в качестве инструмента реализации стратегии устойчивого разви- 
тия, долгосрочные цели автоматически получают приоритет. Соответственно, переход к зеленому росту означает усиление внимания к отдаленным последствиям принятых решений. Эколого-ресурсный аспект в данном отношении играет ключевую роль. С одной стороны, ряд природных благ являются невозобновляемыми, а скорость большинства возобновляемых ограничена по сравнению с темпами их потребления. В этой связи возникает проблема межвременного перераспределения. С другой стороны, нарушение экологического баланса в результате деятельности человека приводит к неблагоприятным последствиям в будущем, которые сложно спрогнозировать.

В современной экономике проблема сопоставления разновременных выгод и затрат решается с помощью дисконтирования. От принятой ставки дисконта (процента) зависит степень учета отдаленных результатов в настоящем. Чем ниже ее уровень, тем больше ценятся будущие выгоды, и наоборот. Однако возникают большие сомнения, насколько точно человек может оценить важность тех или иных благ в своем будущем по сравнению с настоящим. И даже если допустить, что люди умеют четко прогнозировать свои потребности, вряд ли они могут отвечать за мнение будущих поколений (Daly, Farley, 2011). В данной ситуации возможности решения проблемы исключительно средствами оптимизации ограничены, а проблема межвременного распределения, по мнению ряда известных экономистов (Solow, 1993), носит в первую очередь моральный характер. В свою очередь, необходимость обращения к понятию морали еще раз подчеркивает важность институционального аспекта для концепции зеленого роста и указывает на неизбежность сохранения определенного уровня субъективности.

Несмотря на значимость проблемы межвременного распределения, ее решения недостаточно для обеспечения устойчивого роста в долгосрочной перспективе. Учитывая абсолютную ограниченность, природные ресурсы не могут оставаться его источником бесконечно долго. Осознание этого факта приводит к увеличению сторонников необходимости полного отказа от экономического роста (есоnomy of degrowth), подхода, сфокусированного на обеспечении устойчивого развития экономики при стабильном уровне потребления (Victor, Rosenbluth, 2007). В данном контексте важным условием перехода к зеленому росту является поиск внутренних источников, не связанных с дополнительным использованием природных ресурсов.

4. Эндогенныц̆ характер зеленого росma. В экономической науке принято выделять теории экзогенного и эндогенного роста. Первая предполагает, что экономика растет под воздействием внешних по отношению к экономической системе факторов (приток труда, капитала, новых технологий). Вторая нацелена на объяснение экономического прогресса действием сил, которые формируются внутри системы. К таким силам относят эффект масштаба, инновационные процессы и связанные с ними положительные внешние эффекты от распространения знаний, обучения (learning by doing) и пр. (Aghion, Howitt, 2009).

Очевидно, что при формировании концепции зеленого роста приоритет должен отдаваться эндогенным факторам. Одним из таких, например, является эффект экологической кривой Кузнеца, суть которого заключается в том, что по мере роста доходов после определенного порога в уровне благосостояния тенденция увеличения загрязнения затухает и дальнейший рост экономики сопровождается улучшением качества окружающей среды. Хотя в основе такого эффекта лежат разные причины (Brock, Taylor, 2005) и его действие может быть ограничено, поиск и поддержание подобных тенденций во многом будут предопределять успех концепции зеленого роста.

Кроме четырех перечисленных аспектов, при исследовании взаимосвязи экономического роста и экологической устойчивости могут выделятся и другие. Тем не менее, если рассматривать концепцию зеленого роста в контексте сложившегося в экономической науке подхода к проблеме роста в целом, то приоритетное внимание сохранению природных активов, институциональный уклон, ориентация на долгосрочные цели и эндогенный характер выступают в качестве ее наиболее важных отличительных черт. 


\section{Формирование политики перехода к зеленому росту}

Успех перехода к зеленому росту во многом зависит от того, насколько полно рассмотренные выше аспекты учитываются в экономической политике. Последняя, как правило, направлена на достижение целей развития экономики через регулирование спроса и предложения. Поскольку переход к зеленому росту требует переориентации экономики на более долгосрочные цели, связанные с сохранением природных активов, содержание политики также будет меняться. Ее задачей должно стать формирование экономической модели, способной поддерживать приемлемый с позиции экологической устойчивости и необходимости сохранения природных активов баланс спроса и предложения.

Рассматривая изменения в экономической политике как важнейшее условие перехода к зеленому росту, их оценку целесообразно структурировать в соответствии с объектом регулирования. В данном контексте можно выделить два принципиальных направления - регулирование спроса и регулирование предложения. Несмотря на их очевидную взаимосвязь и взаимозависимость, характер политики в рамках указанных направлений и ее возможности существенно отличаются.

Среди традиционных, рыночно-ориентированных, экономистов много сторонников политики предложения. По их мнению, она в наименьшей степени искажает условия конкуренции и способствует повышению эффективности использования ресурсов, что в конечном итоге должно способствовать снижению воздействия на окружающую среду и сохранению природных активов. К данному направлению экономической политики относятся меры, ориентированные на производителя. В контексте перехода к зеленому росту их реализация подразумевает содействие внедрению экологически безопасных, ресурсо- и энергосберегающих технологий, а также расширению деятельности по восстановлению экосистем.

Очевидным преимуществом политики предложения с позиции экологической устойчивости является ее непосредственная направленность на достижение конкретных (целевых) параметров состояния окружающей среды (использования ресурсов). Наличие четких количественных ориентиров существенно упрощает по сравнению с политикой спроса процесс разработки мер по сохранению природных активов и оценку их эффективности. Регулирование спроса, в свою очередь, обычно предполагает достижение целей зеленого роста не напрямую, а через воздействие на потребительское поведение, выступая в большей степени как косвенный инструмент. В то же время необходимо понимать, что потенциал регулирования предложения в отношении природных активов ограничен физически. В глобальном плане ресурсы биосферы лимитированы и не могут быть воспроизведены сверх естественно заданных границ. Следовательно, в условиях постоянного роста потребностей регулирование спроса становится ключевым фактором достижения экологической устойчивости.

В целом понимание процессов и сил, которые определяют взаимодействие спроса и предложения, является первостепенным условием разработки адекватной модели и формирования эффективной политики зеленого роста. Важными факторами в данном случае выступают уровень и временной горизонт принятия решений. В зависимости от их сочетания могут меняться приоритет в использовании тех или иных мер политики зеленого роста, оптимальный набор инструментов.

На уровне отдельных стран в краткосрочном периоде вполне оправдан приоритет мер по регулированию предложения. Более того, в условиях глобализации возможности контроля спроса на уровне одной страны ограничены, даже если это такие крупные экономики, как США и Китай. Следовательно, модель зеленого роста отдельного государства может опираться в первую очередь на факторы предложения (технологии, инновации и т. п.). Однако без учета спроса такая модель упускает из поля зрения ряд внешних эффектов. Одним из них является так называемой парадокс Джевонса, суть которого состоит в том, что повышение эффективности производства делает продукт (услугу) дешевле, приводя в конечном итоге к увеличению потребле- 
ния, а значит и воздействия на окружающую среду. Также важно учитывать внешние эффекты, которые определяются глобальным характером экологических проблем. Например, улучшение состояния окружающей среды за счет политики предложения в одной стране может являться следствием переноса опасных производств в другие страны, где природоохранные ограничения мягче. В результате в глобальном масштабе будет наблюдаться истощение природных активов. Поэтому при разработке глобальной долгосрочной модели, несмотря на важность регулирования предложения, стратегическая роль должна отводиться факторам спроса, без учета которых вряд ли возможен окончательный переход к зеленому росту в условиях абсолютной ограниченности ресурсов.

Переходя в контексте вышесказанного к рассмотрению проблемы в рамках Республики Беларусь, необходимо принимать во внимание как требования глобальной стратегии, так и особенности белорусской экономики, ее конкурентные преимущества и проблемы. Учитывая сравнительно небольшой размер внутреннего рынка и высокую зависимость от внешней торговли, политика спроса имеет ограниченный потенциал для регулирования экономического роста нашей страны (Деревяго, 2019b). Это не означает, что при разработке модели и формировании политики зеленого роста данный фактор должен игнорироваться. С одной стороны, высокая зависимость от внешнего спроса предполагает необходимость учета мировой тенденции к увеличению популярности экологически безопасных товаров и услуг, экологизации потребления в целом. С другой стороны, регулирование внутреннего спроса является важным фактором формирования потребительского поведения в целом и отношения субъектов экономики к природной среде в частности. В этой связи большое значение имеют институциональные аспекты политики зеленого роста, которые затрагивают широкий круг инструментов воздействия на потребителя, включая экологические стандарты, налоги, субсидии и пр.

Тем не менее на национальном уровне фактор предложения во многих случаях ста- новится определяющим для повышения конкурентоспособности экономики. Если глобальный уровень по своей сути не предполагает конкуренции, то успех развития отдельных стран во многом зависит от наличия конкурентных преимуществ в международном разделении труда, что особенно актуально для малых стран с высокой зависимостью от внешнего рынка, таких как Беларусь. При рассмотрении в данном контексте процесса перехода к зеленому росту на первый план выходит роль политики предложения в создании конкурентных зеленых технологий и обеспечении конкурентоспособности зеленого сектора в целом. В более отдаленной перспективе такая политика может стать фактором специализации страны на выпуске зеленых товаров и услуг в рамках международного разделения труда.

Формирование конкурентных преимуществ в зеленом секторе в первую очередь означает снижение стоимости, поскольку фактор цены на сегодняшний день является основным препятствием широкого внедрения зеленых технологий. Для минимизации затрат наиболее важную роль играют два аспекта - инновации и инфраструктура. Если инновационная деятельность ориентирована на поиск новых, более эффективных технологий, то развитие инфраструктуры является главным условием обеспечения эффекта масштаба в производстве и использовании экологически безопасных товаров и услуг, без которого вряд ли возможно достижение их конкурентной стоимости. Поэтому приоритетом политики предложения должны стать стимулирование зеленых инноваций и развитие зеленой инфраструктуры.

C учетом вышесказанного на рис. 1 представлена концептуальная схема модели перехода к зеленому росту. На ней отражены основные элементы, которые определяют структуру экономики и направленность экономических процессов с позиции их влияния на природную среду. Представленная схема может быть детализирована в рамках выделенных блоков при необходимости более глубокого анализа конкретных аспектов зеленого роста.

Рассматривая эту схему, стоит отметить, что конечной целью перехода к зеле- 


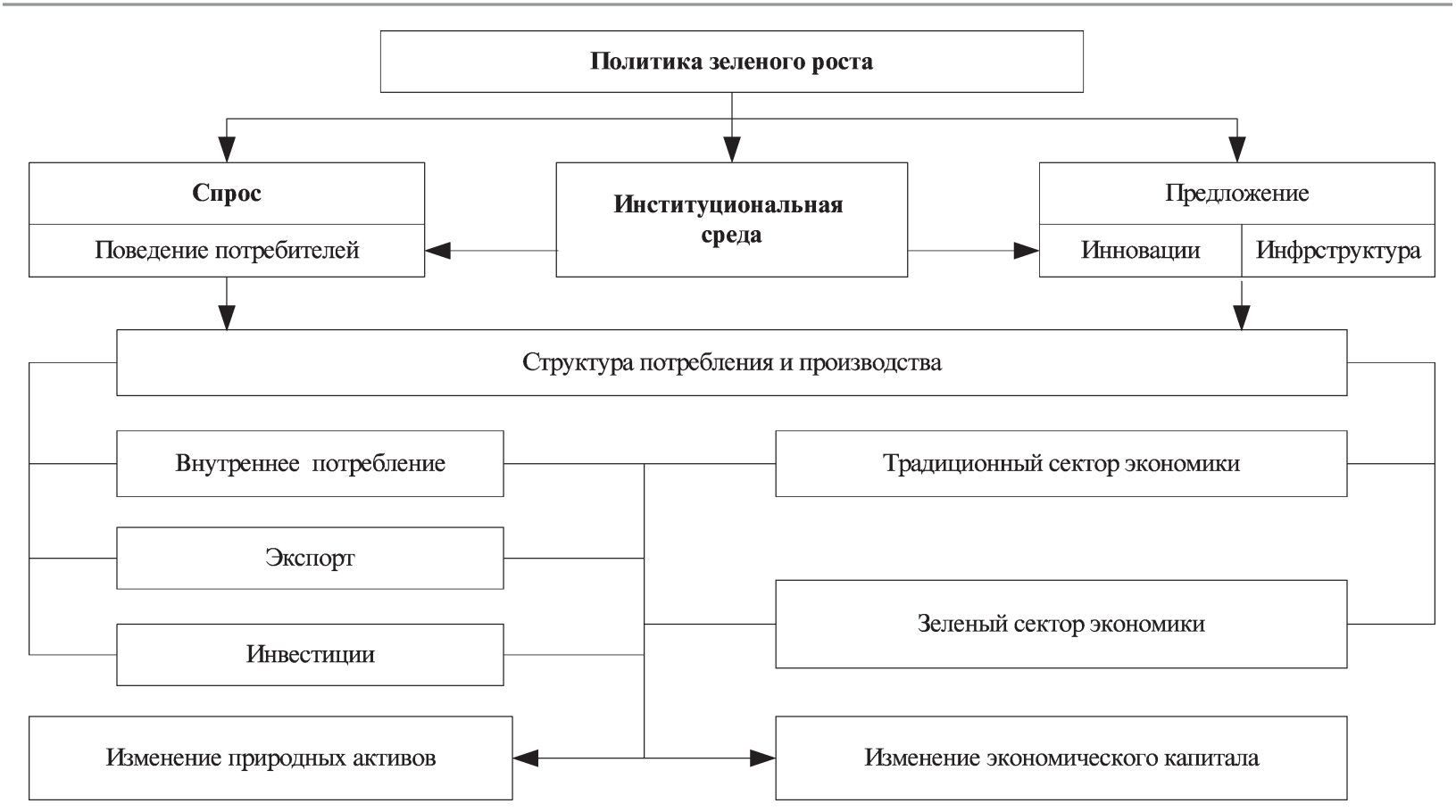

Рис. 1. Концептуальная схема модели перехода к зеленому росту

Источник. Авторская разработка.

ному росту является формирование условий, в которых сам процесс зеленого роста станет эндогенным, способным к самоподдержанию без дополнительного внешнего регулирования. В данном отношении ключевая роль отводится институтам. В идеальном случае формирование благоприятной институциональной среды может исключить необходимость реализации специальных мер экономической политики для достижения оптимального с точки зрения зеленого роста баланса спроса и предложения.

Тем не менее сам переход к зеленому росту вряд ли возможен естественным путем без целенаправленного регулирования со стороны государства. Этим обуславливается наличие в схеме верхнего блока. В данном контексте важной частью моделирования становится оценка реакции экономической системы на применение тех или иных инструментов политики зеленого роста. Их эффективность во многом определяется способностью формировать необходимый баланс спроса и предложения, направленный на приоритетное развитие зеленого сектора и сохранение природных активов, одновременно обеспечивая положительное изменение экономического ка- питала. Последний в зависимости от характера модели может трактоваться широко и соотноситься с ВВП, физическим капиталом, включать в себя физический и человеческий капиталы, иные элементы.

В рамках предложенной схемы анализ процессов, связанных с переходом к зеленому росту, требует их количественного измерения и приведения оценок в сопоставимый вид. Последнее является одним из главных препятствий для построения адекватной модели и формирования надежной системы получения информации, необходимой для принятия эффективных решений. В первую очередь это касается различных экологических элементов, разнородность которых усугубляет проблему сопоставимости. Ее решение требует организации соответствующей системы статистического учета.

Стоит отметить, что в Беларуси в последнее время существенно улучшилось качество информационного обеспечения в области природных активов. В частности, с 2017 г. в соответствии с рекомендациями ОЭСР в статистическом сборнике «Охрана окружающей среды в Республике Беларусь» публикуются показатели зеленого роста. Тем не менее, если сравнивать с прак- 
тикой Европейского Союза, пока учет не охватывает ряд важных для характеристики использования природных активов показателей.

Также важным аспектом совершенствования статистического обеспечения в контексте перехода к зеленому росту является формирование критериев, необходимых для выделения зеленого сектора экономики. В данном случае могут быть использованы различные подходы, например ранжирование товаров, услуг, видов деятельности в зависимости от характера их влияния на окружающую среду. При этом градация не обязательно должна ограничиваться зеленым и традиционным секторами. Могут выделяться нейтральные, экологически опасные (разной степени опасности) виды деятельности или виды деятельности, которые способствуют восстановлению природных активов.

Постепенное совершенствование системы статистического учета позволит повысить точность и уровень детализации информации, необходимой для управления процессом перехода к зеленому росту. Чем больше факторов может быть оценено, тем более сложная и адекватная модель может быть построена. Вместе с тем с учетом современного информационного обеспечения повышение уровня детализации ограничивается как недостатком информации, так и проблемами ее сопоставимости. В данных условиях продуктивным будет подход, не основанный на построении комплексной модели, а ориентированный на оценку отдельных ключевых факторов перехода к зеленому росту. На основе анализа теории экономического роста можно выделить следующие подходы:

- оценка влияния институционального фактора. Построение корреляционно-регрессионных зависимостей позволяет выявить влияние отдельных институтов на инновационную активность в зеленом секторе, интенсивность использования и восстановления природных активов и т. п.;

- оценка инновационного развития. Ряд моделей дает возможность оценить влияние экзогенных и эндогенных инноваций на темпы экономического роста. Для перехода к зеленому росту важно оценить влияние инноваций на развитие зеленого сектора;
- оценка эффективности отдельных инструментов экономической политики. В частности, для перехода к зеленому росту важным фактором является смещение налогового бремени на экологически опасные виды деятельности и продукты;

- оценка влияния эффекта масштаба на динамику роста и пр.

Анализ процесса перехода к зеленому росту в рамках предложенной на рис. 1 схемы не ограничивается перечисленными подходами. В зависимости от того, какие факторы приняты ключевыми, могут применяться самые различные методы и модели. Например, для оценки углеродоемкости конечного продукта часто используется модель межотраслевого баланса, которая позволяет учесть экологические параметры промежуточного потребления. Поскольку одну из важнейших ролей в процессе экономического роста играют инвестиции, далее сосредоточим внимание на оценке инвестиционного фактора.

\section{Инвестиции как фактор перехода к зеленому росту}

Ряд направлений теории экономического роста рассматривают инвестиции в качестве его ключевого фактора. Инвестиции, являясь источником формирования капитала и повышения его производительности, способствуют увеличению выпуска продукции. При этом само понятие капитала все чаще трактуется широко, включая не только физический, но и природный, человеческий, иные виды капитала.

Роль инвестиций при переходе к зеленому росту особенно усиливается с учетом того, что последний предполагает технологическую перестройку. В данном случае важна не только абсолютная величина инвестиционных вложений, но и их структура, которая должна способствовать увеличению доли зеленого сектора в экономике. Более того, учитывая, что одной из целевых установок концепции зеленого роста является ограничение потребления природного вещества и энергии, в долгосрочной перспективе именно инвестиции, а не потребление, могут рассматриваться в качестве стабильного источника экономического роста. Для этого необходимо обеспечить 
приоритетные условия инвестирования в сохранение природных активов (прирост природного капитала), экологически безопасные технологии, зеленые инновации и зеленую инфраструктуру.

Исходя из вышесказанного при анализе инвестиционного фактора важно учитывать три аспекта:

абсолютный уровень инвестиций;

соотношение инвестиций и потребления в ВВП и возможность замещения последнего первыми;

структура инвестиций в разрезе их влияния на состояние природных активов.

C позиции зеленого роста, последний аспект является первичным. Увеличение доли инвестиций, направленных на развитие зеленого сектора, повышение привлекательности последнего для инвесторов будут способствовать расширению инвестиционных возможностей. В свою очередь, это станет фактором роста инвестиций в абсолютном выражении. Одновременно повышение эффективности использования сырья и энергии за счет развития зеленого сектора при соответствующих институциональных условиях приведет к высвобождению средств в сфере потребления. Последние могут стать дополнительным источником инвестиций для зеленого сектора, что сделает структуру инвестиций еще более благоприятной для зеленого роста экономики.

Рассматривая возможности реализации подобного сценария в Республике Беларусь, нужно учитывать, что в последние годы экономика страны испытывает хронический дефицит инвестиций. Их доля ${ }^{3}$ в ВВП существенно ниже порога инвестиционной безопасности (25\%) и в 2019 г. составила менее 22\%, а в 2016-2017 гг. не превышала 20\%. В условиях очевидной необходимости активизации инвестиционной деятельности наращивание инвестиций за счет зеленого сектора позволит существенно ускорить переход к зеленому росту.

Очередной кризис мировой экономики только способствует подобному варианту развития событий. Кризисное время

3 В данном случае речь идет об инвестициях в основной капитал. часто становится благоприятным периодом для политики зеленого кейнсианизма (Jacobs, 2013). Поскольку правительства вынуждены тратить средства на поддержку экономики, инвестиции в зеленый сектор рассматриваются одним из приоритетов как с экономической, так и с экологической точки зрения. С одной стороны, падение доходности в экономике в целом делает даже малодоходные экологически ориентированные проекты сравнительно выгодными. С другой стороны, дополнительные инвестиции в зеленый сектор ускоряют инновационную активность и способствуют быстрому повышению эффективности зеленых технологий. Опыт развитых стран как во время кризиса 2008-2009 гг., так и в условиях современного кризиса ${ }^{4}$ показывает, что зеленые инвестиции являются одним из наиболее приоритетных инструментов правительственной поддержки.

Реализация эффективной политики по привлечению инвестиций в зеленый сектор требует решения как минимум двух задач: формализации самого зеленого сектора и определения критериев эффективности. Что касается первой задачи, то на современном этапе официальной статистикой зеленый сектор не рассматривается как отдельный объект учета. В отсутствие формализации может быть уместной дифференциация различных видов деятельности, а в более детализированном варианте - технологий и производств, в зависимости от уровня воздействия на окружающую среду. В данном случае к зеленому сектору можно отнести те из них, которые способствуют ее улучшению и обеспечивают сохранение природных активов. Остальные виды деятельности и технологии также важно ранжировать согласно их экологической опасности.

Что касается критерия эффективности, то в макроэкономическом контексте при его разработке целесообразно ориентироваться на показатель добавленной стоимости (Быков, Колб, 2016). Хотя с чисто рыночной точки зрения прибыль на единицу инвестиций является более уместным параметром, добав-

4 В начале 2020 г. Европейский союз одобрил так называемую программу «Green deal», которая предполагает выделение 572 млрд евро на зеленые инвестиции. 
ленная стоимость включает важные для роста общего благосостояния компоненты, такие как заработная плата и налоги. Поэтому для оценки влияния инвестиций на экономический рост целесообразно использовать показатель добавленной стоимости на рубль активов. Чем он выше, тем более сильное воздействие на темпы роста оказывают инвестиции в активы.

В рамках представленного исследования был проведен расчет показателя отношения добавленной стоимости к долгосрочным активам $\left(R_{a e}\right)$ в разрезе видов экономической деятельности. Именно данный показатель, а не активы в целом, взят для оценки, поскольку обычно долгосрочные активы, в том числе основные средства, являются целевым объектом инвестиций.
В табл. 1 представлены результаты расчетов за 2017-2018 гг. для отраслей, которые в большей степени относятся к реальному сектору экономики. При этом стоит отметить, что максимальные оценки были получены в образовании, финансовом секторе, прочих видах услуг. Это означает, что инвестиции в данные виды деятельности дают наибольший эффект для роста экономики. Более того, приоритетное развитие сферы услуг в целом соответствует требованиям зеленого роста. В то же время при оценке структуры экономики необходимо понимать, что в реальности невозможно полностью отказаться от развития ряда отраслей, в первую очередь инфраструктурных, несмотря на их меньшую эффективность. Поэтому основное внимание в дан-

Создание добавленной стоимости на единицу долгосрочных активов

Таблица 1

\begin{tabular}{|c|c|c|c|c|c|c|}
\hline \multirow[t]{2}{*}{ Вид деятельности } & \multicolumn{2}{|c|}{$\begin{array}{l}\text { Добавленная } \\
\text { стоимость, } \\
\text { млн руб. }\end{array}$} & \multicolumn{2}{|c|}{$\begin{array}{c}\text { Долгосрочные } \\
\text { активы на начало } \\
\text { года, млн руб. }\end{array}$} & \multicolumn{2}{|c|}{$\begin{array}{c}\text { Отношение добавлен- } \\
\text { ной стоимости } \\
\text { к долгосрочным } \\
\text { активам }\left(R_{a v}\right)\end{array}$} \\
\hline & 2017 & 2018 & 2017 & 2018 & 2017 & 2018 \\
\hline Республика Беларусь & 91740,8 & 104786,6 & 165609,4 & 178389,7 & 0,55 & 0,59 \\
\hline Сельское, лесное и рыбное хозяйство & 8000,7 & 8061,0 & 21301,7 & 21886,3 & 0,38 & 0,37 \\
\hline Горнодобывающая промышленность & 722,3 & 942,1 & 2951,1 & 3183,1 & 0,24 & 0,30 \\
\hline Обрабатывающая промышленность & 22872,4 & 26002,7 & 52575,9 & 56562,7 & 0,44 & 0,46 \\
\hline $\begin{array}{l}\text { В том числе производство: } \\
\text { продуктов питания, напитков } \\
\text { и табачных изделий } \\
\end{array}$ & 5703,9 & 5847,0 & 8556,7 & 9774,9 & 0,67 & 0,60 \\
\hline $\begin{array}{l}\text { текстильных изделий, одежды, } \\
\text { изделий из кожи и меха }\end{array}$ & 1530,2 & 1590,7 & 2070,1 & 2149,8 & 0,74 & 0,74 \\
\hline $\begin{array}{l}\text { изделий из дерева и бумаги; } \\
\text { полиграфическая деятельность } \\
\text { и тиражирование }\end{array}$ & 1367,6 & 1974,4 & 7907,2 & 7801,9 & 0,17 & 0,25 \\
\hline кокса и продуктов нефтепереработки & 735,7 & 840,6 & 5303,9 & 5922,5 & 0,14 & 0,14 \\
\hline химических продуктов & 3645,3 & 4647,1 & 8350,2 & 8767,4 & 0,44 & 0,53 \\
\hline $\begin{array}{l}\text { основных фармацевтических } \\
\text { продуктов и препаратов }\end{array}$ & 603,1 & 664,4 & 672,7 & 747,0 & 0,90 & 0,89 \\
\hline $\begin{array}{l}\text { резиновых и пластмассовых } \\
\text { изделий, прочих неметаллических } \\
\text { минеральных продуктов }\end{array}$ & 2355,0 & 2414,4 & 6823,5 & 7243,8 & 0,35 & 0,33 \\
\hline $\begin{array}{l}\text { металлургическое; производство } \\
\text { готовых металлических изделий, } \\
\text { кроме машин и оборудования }\end{array}$ & 1259,5 & 1512,6 & 4056,1 & 4382,9 & 0,31 & 0,35 \\
\hline $\begin{array}{l}\text { вычислительной, электронной } \\
\text { и оптической аппаратуры }\end{array}$ & 626,0 & 678,4 & 660,8 & 705,1 & 0,95 & 0,96 \\
\hline электрооборудования & 678,9 & 683,4 & 1056,3 & 1115,8 & 0,64 & 0,61 \\
\hline $\begin{array}{l}\text { машин и оборудования, не } \\
\text { включенных в другие группировки }\end{array}$ & 2137,9 & 2689,8 & 3586,3 & 4019,4 & 0,60 & 0,67 \\
\hline $\begin{array}{l}\text { транспортных средств } \\
\text { и оборудования }\end{array}$ & 781,6 & 902,9 & 2292,3 & 2637,6 & 0,34 & 0,34 \\
\hline $\begin{array}{l}\text { прочих готовых изделий; ремонт, } \\
\text { монтаж машин и оборудования }\end{array}$ & 1447,7 & 1557,0 & 1239,8 & 1294,5 & 1,17 & 1,20 \\
\hline
\end{tabular}


Окончание табл. 1

\begin{tabular}{|c|c|c|c|c|c|c|}
\hline \multirow[t]{2}{*}{ Вид деятельности } & \multicolumn{2}{|c|}{$\begin{array}{l}\text { Добавленная } \\
\text { стоимость, } \\
\text { млн руб. }\end{array}$} & \multicolumn{2}{|c|}{$\begin{array}{l}\text { Долгосрочные } \\
\text { активы на начало } \\
\text { года, млн руб. }\end{array}$} & \multicolumn{2}{|c|}{$\begin{array}{c}\text { Отношение добавлен- } \\
\text { ной стоимости } \\
\text { к долгосрочным } \\
\text { активам }\left(R_{a v}\right)\end{array}$} \\
\hline & 2017 & 2018 & 2017 & 2018 & 2017 & 2018 \\
\hline $\begin{array}{l}\text { Снабжение электроэнергией, газом, } \\
\text { паром, г орячей водой } \\
\text { и кондиционированным воздухом }\end{array}$ & 3441,1 & 3930,4 & 18688,7 & 20494,2 & 0,18 & 0,19 \\
\hline $\begin{array}{l}\text { Водоснабжение; сбор, обработка } \\
\text { и удаление отходов, деятельность } \\
\text { по ликвидации загрязнений }\end{array}$ & 771,7 & 866,5 & 2554,8 & 2803,6 & 0,30 & 0,31 \\
\hline Строительство & 5560,8 & 6502,4 & 18433,4 & 20659,7 & 0,30 & 0,31 \\
\hline $\begin{array}{l}\text { Оптовая и розничная торговля; ремонт } \\
\text { автомобилей и мотоциклов }\end{array}$ & 10948,9 & 12257,8 & 7954,0 & 9572,2 & 1,38 & 1,28 \\
\hline $\begin{array}{l}\text { Транспорт, складирование, почтовая } \\
\text { и курьерская деятельность }\end{array}$ & 6085,0 & 7188,3 & 23735,2 & 23818,5 & 0,26 & 0,30 \\
\hline $\begin{array}{l}\text { Услуги по временному проживанию } \\
\text { и питанию }\end{array}$ & 928,3 & 1039,4 & 1164,8 & 1531,1 & 0,80 & 0,68 \\
\hline Информация и связь & 5357,1 & 6570,6 & 3807,5 & 4118,0 & 1,41 & 1,60 \\
\hline Творчество, спорт, развлечения и отдых & 984,3 & 1129,0 & 693,1 & 755,5 & 1,42 & 1,49 \\
\hline
\end{tabular}

Источник. Авторские расчеты на основе: URL: http://dataportal.belstat.gov.by/Indicators

ной статье сосредоточено на реальном секторе, оптимизация структуры которого играет первоочередное значение для перехода к зеленому росту. Как видно из табл. 1, наилучшие показатели отмечаются в сфере информационных технологий, торговле, фармацевтической промышленности, электронике и некоторых других отраслях 5 .

Поскольку условием перехода к зеленому росту является сохранение природных активов, при оценке инвестиций важно учитывать воздействие объекта вложений на окружающую среду. На сегодняшний день не существует единого подхода к измерению такого воздействия в стоимостном выражении. Точная оценка требует учета большого количества информации. При ее отсутствии в экономике часто используются так называемые прокси-переменные, которые, как предполагается, тесно коррелируют с основным параметром и могут использоваться для его оценки. Так, в качестве прокси-измерителя воздействия на окружающую среду вполне подходит показатель массы потребленных сырья, материалов и энергоресурсов, учет которого ведется в большинстве европейских стран.

5 Для более точных оценок нужно учитывать вклад отдельных отраслей (производство нефтепродуктов, горнодобывающая промышленность) в рост ВВП за счет поступлений от внешнеэкономической деятельности, которые учитываются в косвенных налогах.
Однако в официальной белорусской статистике данный показатель отсутствует.

Исходя из наличия статистической информации, для измерения воздействия на окружающую среду могут использоваться показатели выбросов вредных веществ, образования отходов, потребления водных ресурсов и пр. При этом один параметр не даст полной картины, а при учете нескольких параметров одновременно возникает проблема сопоставимости. Одним из вариантов решения данной проблемы является использование относительных, а не абсолютных величин. В табл. 2 в разрезе видов деятельности представлены показатели вклада в общий уровень воздействия на окружающую среду по 3 параметрам - выбросы в атмосферу, образование отходов и использование воды и их соотношение с вкладом в создание добавленной стоимости. Итоговый показатель, коэффициент относительной экологической эффективности добавленной стоимости $\left(K_{\text {ave }}\right)$, рассчитывается по формуле

$$
K_{\text {ave }}=\frac{\Delta A V \cdot n}{\sum_{i=1}^{n} \Delta E I_{i}}
$$

где $\triangle A V-$ доля добавленной стоимости отрасли в общей сумме добавленной стоимости, \%;

$\Delta E I_{i i}$ - доля $i$-го воздействия на окружающую среду, \%;

$n$ - количество видов воздействия. 
Соотношение вклада вида деятельности в создание добавленной стоимости и вклада в воздействие на окружающую среду

\begin{tabular}{|c|c|c|c|c|c|c|c|}
\hline \multirow{3}{*}{ Вид деятельности } & \multicolumn{4}{|c|}{ Доля вида деятельности в общем объеме в 2017 г., \% } & \multirow{3}{*}{$\begin{array}{c}\text { Доля в общем } \\
\text { объеме } \\
\text { добавленной } \\
\text { стоимости } \\
\text { в } 2017 \text { г., \% }\end{array}$} & \multirow{2}{*}{\multicolumn{2}{|c|}{$\begin{array}{c}\text { Коэффициент } \\
\text { относительной } \\
\text { экологической } \\
\text { эффективности } \\
\text { добавленной } \\
\text { стоимости }\left(K_{a v e}\right)\end{array}$}} \\
\hline & \multirow[t]{2}{*}{$\begin{array}{c}\text { Выбросы } \\
\text { в } \\
\text { атмосферу }\end{array}$} & \multirow[t]{2}{*}{$\begin{array}{c}\text { Исполь- } \\
\text { зование } \\
\text { воды }\end{array}$} & \multirow[t]{2}{*}{$\begin{array}{l}\text { Образо- } \\
\text { вание } \\
\text { отходов }\end{array}$} & \multirow[t]{2}{*}{$\begin{array}{c}\text { Сумма } \\
\text { долей } \\
(2+3+4)\end{array}$} & & & \\
\hline & & & & & & 2017 г. & 2018 г. \\
\hline Республика Беларусь & 100.0 & 100,0 & 100,0 & 300,0 & 100,0 & 1,00 & 1.00 \\
\hline $\begin{array}{l}\text { Сельское, лесное и рыбное } \\
\text { хозяйство }\end{array}$ & 13,32 & 35,11 & 1,12 & 49,56 & 8,72 & 0,53 & 0,47 \\
\hline $\begin{array}{l}\text { Горнодобывающая } \\
\text { промышленность }\end{array}$ & 0,37 & 0,54 & 1,82 & 2,73 & 0,79 & 0,86 & 0,88 \\
\hline $\begin{array}{l}\text { Обрабатывающая } \\
\text { промышленность }\end{array}$ & 14,12 & 14,21 & 86,22 & 114,55 & 24,93 & 0,65 & 0,65 \\
\hline $\begin{array}{l}\text { В том числе производство: } \\
\text { продуктов питания, напитков } \\
\text { и табачных изделий }\end{array}$ & 1,28 & 4,14 & 3,70 & 9,12 & 6,22 & 2,04 & 1,75 \\
\hline $\begin{array}{l}\text { текстильных изделий, одежды, } \\
\text { изделий из кожи и меха }\end{array}$ & 0,29 & 0,70 & 0,23 & 1,21 & 1,67 & 4,12 & 4,00 \\
\hline $\begin{array}{l}\text { изделий из дерева и бумаги; } \\
\text { полиграфическая деятельность } \\
\text { и тиражирование }\end{array}$ & 0,71 & 1,14 & 2,24 & 4,09 & 1,49 & 1,09 & 1,31 \\
\hline $\begin{array}{l}\text { кокса и продуктов } \\
\text { нефтепереработки }\end{array}$ & 6,76 & 1,16 & 0,14 & 8,06 & 0,80 & 0,30 & 0,29 \\
\hline химических продуктов & 1,06 & 4,35 & 70,49 & 75,90 & 3,97 & 0,16 & 0,18 \\
\hline $\begin{array}{l}\text { основных фармацевтических } \\
\text { продуктов и препаратов }\end{array}$ & 0,01 & 0,04 & 0,01 & 0,06 & 0,66 & 32,08 & 27,16 \\
\hline $\begin{array}{l}\text { резиновых и пластмассовых } \\
\text { изделий, прочих } \\
\text { неметаллических минеральных } \\
\text { продуктов }\end{array}$ & 1,89 & 1,15 & 6,12 & 9,16 & 2,57 & 0,84 & 0,76 \\
\hline $\begin{array}{l}\text { металлургическое; производство } \\
\text { готовых металлических изделий, } \\
\text { кроме машин и оборудования }\end{array}$ & 0,94 & 0,40 & 1,37 & 2,72 & 1,37 & 1,51 & 1,53 \\
\hline $\begin{array}{l}\text { вычислительной, электронной } \\
\text { и оптической аппаратуры }\end{array}$ & 0,03 & 0,22 & 0,01 & 0,26 & 0,68 & 7,75 & 7,49 \\
\hline электрооборудования & 0,04 & 0,09 & 0,02 & 0,15 & 0,74 & 14,71 & 12,85 \\
\hline $\begin{array}{l}\text { машин и оборудования, } \\
\text { не включенных в другие } \\
\text { группировки }\end{array}$ & 0,72 & 0,52 & 0,54 & 1,78 & 2,33 & 3,93 & 4,18 \\
\hline $\begin{array}{l}\text { транспортных средств } \\
\text { и оборудования }\end{array}$ & 0,22 & 0,25 & 0,24 & 0,71 & 0,85 & 3,58 & 3,57 \\
\hline $\begin{array}{l}\text { прочих готовых изделий; ремонт, } \\
\text { монтаж машин } \\
\text { и оборудования }\end{array}$ & 0,16 & 0,05 & 1,09 & 1,30 & 1,58 & 3,65 & 3,18 \\
\hline $\begin{array}{l}\text { Снабжение электроэнергией, } \\
\text { газом, паром, горячей водой } \\
\text { и кондиционированным } \\
\text { воздухом }\end{array}$ & 4,98 & 15,22 & 0,81 & 21,01 & 3,75 & 0,54 & 0,54 \\
\hline $\begin{array}{l}\text { Водоснабжение; сбор, } \\
\text { обработка и удаление отходов, } \\
\text { деятельность по ликвидации } \\
\text { загрязнений }\end{array}$ & 0,71 & 31,07 & 4,84 & 36,62 & 0,84 & 0,07 & 0,07 \\
\hline Строительство & 0,37 & 1,15 & 2,61 & 4,12 & 6,06 & 4,41 & 4,55 \\
\hline $\begin{array}{l}\text { Оптовая и розничная торговля; } \\
\text { ремонт автомобилей } \\
\text { и мотоциклов }\end{array}$ & 0,18 & 0,13 & 0,90 & 1,21 & 11,93 & 29,59 & 28,11 \\
\hline $\begin{array}{l}\text { Транспорт, складирование, } \\
\text { почтовая и курьерская } \\
\text { деятельность }\end{array}$ & 65,51 & 0,32 & 0,20 & 66,04 & 6,63 & 0,30 & 0,31 \\
\hline $\begin{array}{l}\text { Услуги по временному } \\
\text { проживанию и питанию }\end{array}$ & 0,00 & 1,34 & 0,11 & 1,46 & 1,01 & 2,08 & 2,79 \\
\hline Информация и связь & 0,00 & 0,00 & 0,01 & 0,01 & 5,84 & 1200,45 & 1298,06 \\
\hline $\begin{array}{l}\text { Творчество, спорт, развлечения } \\
\text { и отдых }\end{array}$ & 0,00 & 0,27 & 0,08 & 0,35 & 1,07 & 9,25 & 8,98 \\
\hline
\end{tabular}

Источник. Авторские расчеты на основе: URL: http://dataportal.belstat.gov.by/Indicators; для 2018 г. представлены итоговые расчеты. 
Хотя оценка, основанная на сумме долей, не может считаться полноценной характеристикой воздействия на окружающую среду, она вполне может использоваться для сравнительного анализа, необходимого для решения задачи оптимизации структуры экономики.

Как и в случае с показателем отношения добавленной стоимости к активам, наилучшее значение по коэффициенту относительной экологической эффективности имеют отдельные виды услуг, в том числе финансовый сектор, операции с недвижимым имуществом, образование и пр. Из представленных в табл. 2 существенно выделяется информационный сектор, который практически не оказывает воздействия на окружающую среду при высоком уровне добавленной стоимости. Среди отраслей промышленности наилучшие показатели у фармацевтики, производства электроники и электрооборудования, легкой промышленности.

Понимая всю условность коэффициента $\left(K_{\text {ave }}\right)$, нужно отметить, что его низкое значение не подразумевает полный отказ от инвестиций. Более того, такие инфраструктурные отрасли, как энергетика, водоснабжение, сбор отходов, без которых невозможно функционирование экономики в целом, по своему характеру подразумевают высокое воздействие на окружающую среду. Тем не менее более детальный анализ коэффициента в рамках одного вида деятельности в разрезе типов технологий, производств будет способствовать оптимизации структуры самой отрасли. В частности, несмотря на высокую экологическую опасность энергетики, значение $K_{\text {ave }}$ может сильно различаться для различных способов получения энергии. Соответственно, изменение технологической структуры отрасли является важным фактором перехода к зеленому росту.

Таким образом, предложенный подход к анализу относительной экологической эффективности добавленной стоимости может применяться с различным уровнем детализации как на межотраслевом, так и на внутриотраслевом уровне. В свою очередь, коэффициент $K_{a v e}$ с возможной модификацией вполне может стать критерием для отнесения того или иного вида деятельности (технологии, производства) к зеленому или иному сектору. Это будет способствовать более четкой структуризации экономики в соответствии со схемой на рис. 1, необходимой для формирования адекватной модели зеленого роста и разработки соответствующих мер политики.

С учетом предложенного подхода к анализу определение приоритетных для инвестиций видов деятельности (технологий) может быть основано на использовании интегрального критерия соответствия принципам зеленого роста $\left(I_{g g}\right)$ :

$$
I_{g g}=\sqrt{R_{a v}} \cdot K_{a v e}
$$

Оценка критерия показала, что наиболее приоритетными объектами инвестиций в контексте перехода к зеленому росту являются финансовый, информационный секторы, образование, прочие услуги. Подобные выводы являются очевидными, учитывая характер перечисленных видов деятельности. С позиции оптимизации структуры реального сектора больший интерес представляют результаты расчета интегрального критерия для отраслей добывающей и обрабатывающей промышленности (рис. 2).

Как можно увидеть, в большей степени отвечают требованиям зеленого роста инвестиции в фармацевтику, производство электрооборудования, электроники, ремонт и монтаж машин, легкую промышленность. В то же время производства химического комплекса, горнодобывающей промышленности, деревообработки и металлургии имеют минимальное значение интегрального критерия соответствия. Данные результаты во многом противоречат современным приоритетам республики в инвестиционной деятельности (рис. 3). Соответствующий показатель приоритета $\left(P_{i}\right)$ был рассчитан по формуле

$$
P_{i}=\frac{\Delta I_{i}}{\Delta A V},
$$

где $\Delta I_{i}$ - доля инвестиций в основной капитал данной отрасли в общем объеме инвестиций в основной капитал, \%.

Наибольшие значения показателя приоритета инвестиционной деятельности отмечаются в таких сферах, как операции с 


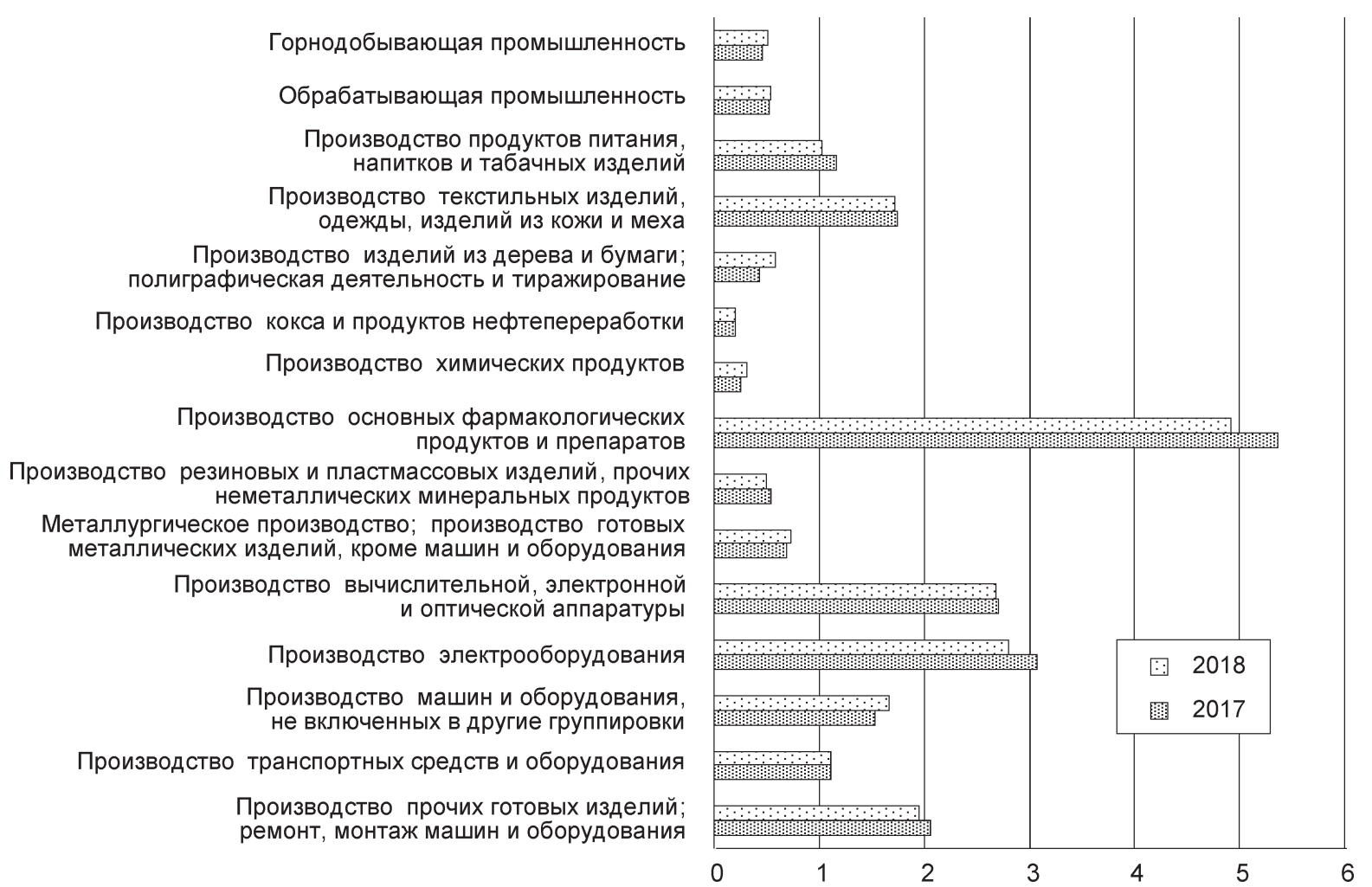

Рис. 2. Значение интегрального коэффициента соответствия принципам зеленого роста для добывающей и обрабатывающей промышленности

Источник. Авторская разработка на основе данных табл. 1, 2.

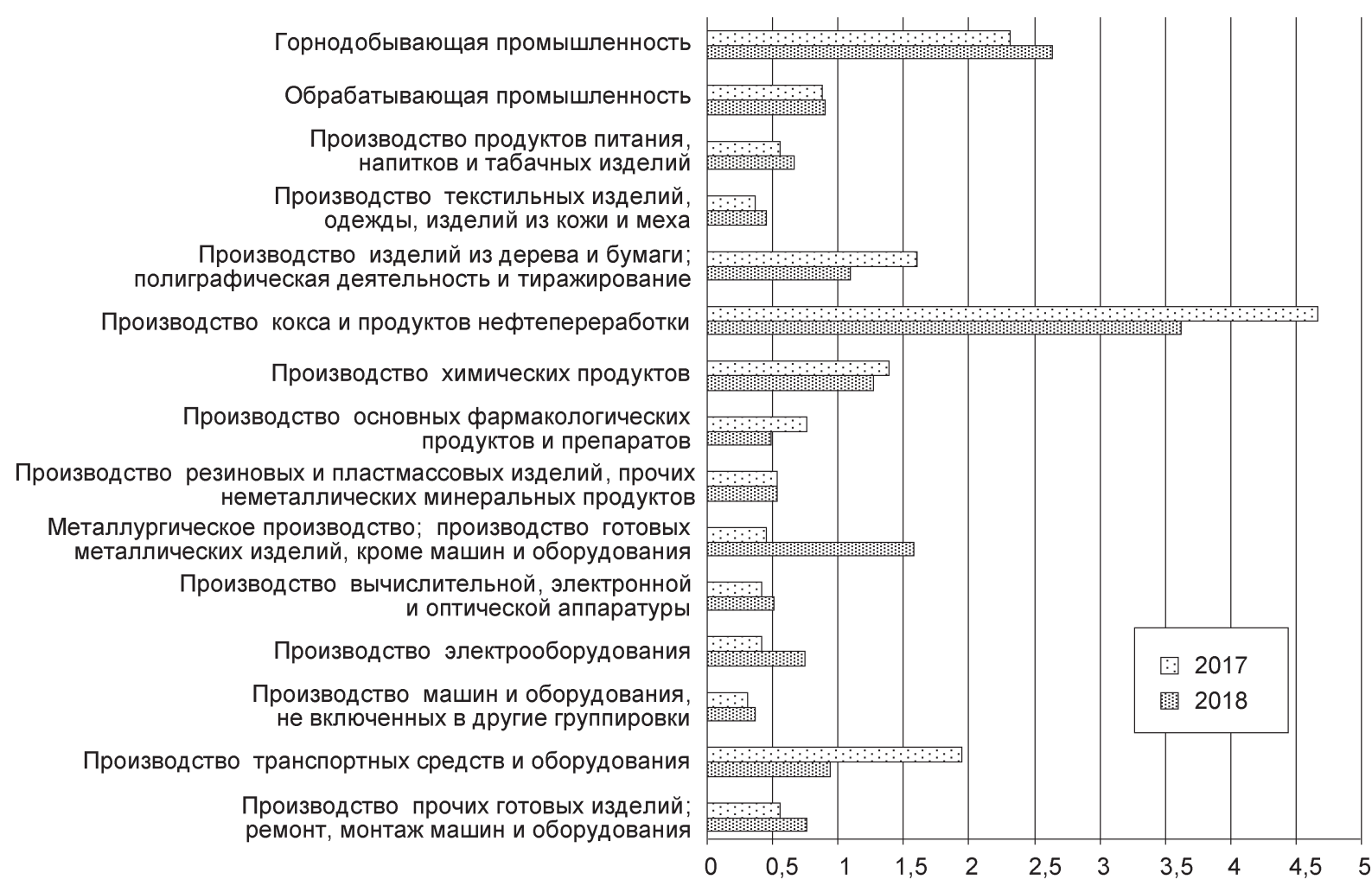

Рис. 3. Показатель приоритета инвестиционной деятельности для добывающей и обрабатывающей промышленности

Источник. Авторские расчеты на основе: URL: http://dataportal.belstat.gov.by/Indicators 
недвижимостью, энергетика (главным образом за счет строительства атомной электростанции), нефтепереработка, горнодобывающая промышленность. Отсюда можно сделать вывод: современная инвестиционная политика в Беларуси не до конца соответствует требованиям зеленого роста.

Нужно подчеркнуть, что представленная методика ориентирована на получение сравнительных оценок. Она может применяться для анализа структуры экономики и принятия решений относительно инвестиционных приоритетов в условиях перехода к зеленому росту. Подобные подходы часто используются в условиях нехватки количественной информации, ограниченной сопоставимости данных, необходимости многокритериальной оценки. В частности, это касается составления различных рейтингов, которые широко применяются в самых разных сферах экономики.

Полученные результаты показывают, что для перехода к зеленому росту необходимы структурные изменения в инвестиционной политике Беларуси. Это может достигаться путем формирования соответствующей системы стимулов, корректировки институциональных условий инвестиционной деятельности, которые будут способствовать повышению инвестиционной привлекательности зеленого сектора и экологически менее опасных видов деятельности и технологий в целом. Одним из вариантов может стать учет коэффициента $K_{a v e}$ при определении стоимости привлечения инвестиций с помощью различных инструментов в рамках инвестиционных рейтингов.

В целом анализ влияния инвестиционного фактора на зеленый рост не ограничивается структурным аспектом. Одной из наиболее актуальных задач в данном направлении является повышение количественной определенности оценок. Это позволит повысить уровень формализации моделей в рамках схемы, представленной на рис. 1, строить более адекватные зависимости, улучшить качество прогнозирования и принимать более эффективные решения. Также важным аспектом является взаимосвязь инвестиционного с институциональным, инфраструктурным, инновационным, иными факторами. В то же вре- мя нужно понимать, что чем больше элементов включено в анализ, тем сложнее достичь необходимого уровня определенности результатов, а значит, более ограничена сфера их применимости. Поэтому соблюдение баланса между полнотой охвата и релевантностью оценок является одним из главных условий результативности исследований в области зеленого роста.

Представленный в статье подход к реализации концепции зеленого роста построен на системной интеграции основных факторов спроса и предложения, от которых зависит возможность постепенного увеличения роли и повышения конкурентоспособности зеленого сектора экономики. Разработанная концептуальная схема может использоваться для моделирования, оценки влияния основных факторов и мер экономической политики на процесс перехода к зеленому росту.

Анализ инвестиционного фактора показал, что в условиях нехватки и ограниченной сопоставимости данных возможности построения адекватных методов количественной оценки ограничены. Тем не менее полученные результаты являются достаточно информативными и могут использоваться для принятия решений. Более того, предложенный подход предоставляет широкое поле для исследований в отношении других факторов, а улучшение информационной обеспеченности позволит получать более точные оценки и строить более адекватные модели. Это будет способствовать реализации эффективной политики по повышению конкурентоспособности зеленого сектора и постепенному переходу к зеленому росту.

\section{СПИСОК ЛИТЕРАТУРЫ (REFERENCES)}

Быков А.А., Колб О.Д. 2016. Показатель «добавленная стоимость национального происхождения в экспорте»: расчет и возможности применения. Белорусский экономический журнал. № 1. C. 128-143. [Bykau A.A., Kolb V.D. 2016. «Domestic value added in exports» index: Computation and possibilities of application. Belorusskiy ekonomicheskiy zhurnal. No 1. PP. 128-143. (In Russ.)] 
Деревяго И.П. 2019а. Зеленый рост экономики: от теории к практике. Минск: Бинера. 160 c. [Dzeraviaha I.P. 2019a. Green growth of economy: from theory to practice. Minsk: Binera. (In Russ.)]

Деревяго И.П. 2019b. Проблемы формирования эффективной политики экономического роста в Республике Беларусь. Белорусский экономический журнал. № 2. С. 25-37. [Dzeraviaha I.P. 2019b. Issues of forming efficient economic growth policy in the Republic of Belarus. Belorusskiy ekonomicheskiy zhurnal. No 2. PP. 2537. (In Russ.)]

Aghion P., Howitt P. 2009. The economics of growth. Cambridge, MA: The MIT Press.

Acemoglu D., Robinson J. 2012. Why nations fail: The origins of power, prosperity, and poverty. New York: Crown publishers.

Brock W., Taylor M. 2005. Economic growth and the environment: A review of theory and empirics.
Handbook of Economic Growth. Vol. 1B. Amsterdam: North-Holland.

Daly H., Farley J. 2011. Ecological economics: Principles and applications. Washington, DC: Island Press.

Jacobs M. 2013. Green Growth. The Handbook of Global Climate and Environment Policy. Oxford: Wiley Blackwell.

Nordhaus W.D., Boyer J. 2000. Warming the world: Economic models of global warming. Cambridge, MA: The MIT Press.

Solow R.M. 1993. An almost practical step toward sustainability. Resources Policy. Vol. 19. Iss. 3. PP. 162-172.

Taylor L. 2004. Reconstructing macroeconomics: Structuralist proposals and critiques of the mainstream. Cambridge, MA: Harvard University Press.

Victor P., Rosenbluth G. 2007. Managing without growth. Ecological Economics. Vol. 61. PP. 492-504.

In citation: Belorusskiy Economicheskiy zhurnal. 2020. No 4. PP. 20-35.

Belarusian Economic Journal. 2020. No 4. PP. 20-35.

\title{
CONDITIONS AND POSSIBILITIES OF ECONOMY TRANSITION TO GREEN GROWTH
}

\author{
Ihar Dzeraviaha ${ }^{1}$ \\ Authors affiliation: ${ }^{1}$ Belarusian State University (Minsk, Belarus). \\ Corresponding author: Ihar Dzeraviaha (1218pd@gmail.com).
}

ABSTRACT. The problem of green growth is becoming more and more urgent. The article examines the provisions of the concept of green growth and the main aspects related to its implementation, including the natural resources issues, taking into account the factor of time, and problems of institutional transformation. As a result of analysis, the conceptual framework is proposed. It integrates and interconnects the main elements that play a key role in the transition to green growth. The article presents an approach to assessing conformity of the investment policy with green growth principles. Taking into account the results of the assessment, conclusions were drawn about the directions of its improvement.

KEYWORDS: green growth, investment, natural capital, economic policy, value added.

JEL-code: E02, E22, O44, Q56.

DOI: $10.46782 / 1818-4510-2020-4-20-35$ 